\title{
Investigation and Analysis of Badminton Shirt Consumption in Chengdu
}

\author{
Chen Mi \\ B.E Students, \\ college of Biomass Science and Engineering, \\ Sichuan University of Chengdu, \\ Sichuan, China.
}

\author{
Zhang Gaopeng \\ (Correspondence author) \\ Associate professor, \\ college of Biomass Science and Engineering, \\ Sichuan University of Chengdu, \\ Sichuan, China.
}

\begin{abstract}
According to the survey questionnaire on the consumption behavior of badminton shirts in Chengdu, from the consumer's habits, colors and styles of badminton shirts, through the form of questionnaire survey, empirical analysis, multiple response analysis and cross-analysis were used to empirically analyze the badminton shirt, the choice and consumption of fans in badminton shirts. The study found that the three main factors that badminton enthusiasts pay more attention to when purchasing badminton shirts are style, color and fabric; badminton enthusiasts tend to buy professional badminton shirts, and pay attention to the beauty of badminton shirts, the comfort of fabrics and In terms of color, badminton enthusiasts tend to buy badminton shirts with pure color and bright colors. In terms of style, badminton fans think that round sleeves and raglan sleeves and round neck collar badminton shirts are more suitable.
\end{abstract}

Keywords-Badminton shirts; Consumer behavior; Clothing styles; Research and analysis

\section{INTRODUCTION}

Sportswear is specialized for sports competitions. Statistics show that with the improvement of people's health awareness and sports facilities, the participation of Chinese people in sports has increased significantly in recent years, the demand for related sports products has increased, and the sportswear industry has developed rapidly. The size of China's sportswear market has increased from 16.2 billion yuan in 2003 to 66.4 billion yuan in 2008. As of 2017, the growth of China's sportswear market has exceeded 200 billion yuan (Anonymous, 2019).

According to data released by the State General Administration of Sports in 2014, China's badminton population has reached 250 million. Statistics in 2018 show that badminton has become one of the sports events with the highest level of mass participation in China (Anonymous,2019). At present, many researches on sportswear are based on the performance of sportswear fabrics (Lou,2019; Liu et al 2019), including the impact of fabric preparation technology on fabric performance. In the field of badminton sports research, researchers pay attention to the tactical analysis of badminton sports, the characteristics of badminton sports (Alder DB et al,2019; Chen et al ,2019), and also include the research on the fabrics and styles of badminton shirts on the thermal and wet comfort and sports comfort of the fabric(Zhou et al,2017; Yang et al ,2017). This article is aimed at badminton enthusiasts in Chengdu. From the perspective of consumers, it analyzes the consumer demand for badminton shirts. Through online and offline questionnaires, we understand the performance and color of badminton shirts in Chengdu.

\section{QUESTIONNAIRE}

\subsection{Survey object}

Badminton enthusiasts refer to a group of social people who love badminton and regularly perform a series of badminton sports related to badminton. The badminton shirt is a clothing for badminton sports that has special sweat wicking technology and pays attention to the smoothness of the upper body movements of the athletes. According to a series of measurements and screenings in different regions and ages.this article determines that the research object is badminton enthusiasts in Chengdu.

\subsection{Questionnaire content design}

Questionnaire surveys are a common method for conducting market surveys and can collect various types of effective information. Among them, for the development of clothing products, the formulation of marketing strategies, and brand promotion methods, it is necessary to conduct questionnaires on target consumers around specific issues. Surveys in order to understand consumer consumption needs, consumption characteristics, consumption habits, etc. So as to make clothing product development more in line with consumer expectations (Cai et al,2018).

Consumer consumption behavior is affected by internal and external dimensions: the external dimensions include political environment, social macroeconomic environment, social culture; the internal dimensions include gender, personal occupation. (Xiong et al,2012).

This article analyzes the consumption behavior of badminton enthusiasts on badminton shirts in three aspects: the consumption habits, tendency to color, and style of badminton 
fans. These three aspects are interconnected. Consumer consumption habits are mainly reflected in purchase considerations, prices, brands etc. separate consumer preference colors and styles from consumer consumption habits, and refine consumers' color. And the consumption choice on the style, thus focusing on analyzing the consumption behavior of badminton enthusiasts on badminton shirts. Questionnaire design single-choice, multiple-choice, and matrix multiple-choice questions cover the consumption habits, preferences, and styles of badminton shirts for badminton lovers of different ages. This article will integrate color psychology and social practice perspectives to conduct empirical research, and analyze the characteristics of badminton shirt consumption behavior of badminton fans in Chengdu.

\subsection{Questionnaire recycling statistics}

This questionnaire was issued on September 29, 2019 through online and offline forms, and random sampling surveys were conducted (Liu et al,2018).The distribution period was 15 days. The survey objects were mainly conducted in professional badminton venues in Chengdu. The online questionnaire was released and collected through the Chengdu badminton club group. The offline questionnaire selected Chengdu city center and suburban badminton courts for investigation. The questionnaires were distributed at irregular intervals mainly in the Sichuan Provincial Gymnasium, Sichuan University Gymnasium, and Southwest Petroleum Badminton Court. A total of 234 questionnaires and 213 questionnaires were returned in this survey. The effective recovery rate was 93\%. Among them, 198 were valid questionnaires, 112 were valid online questionnaires, and 86 were valid offline questionnaires. The following data is used for data summary, and Excel and SPSS are used for data analysis.

\section{QUESTIONNAIRE RESULTS AND ANALYSIS}

\subsection{Basic situation analysis of respondents}

Badminton is a sport that is suitable for all ages. It can be played indoors and outdoors, and the sports place is moderate. As can be seen from Table 1, there are significantly more male respondents than females in the interviewed population. The age span of the interviewed population is relatively large. The majority of the respondents at the age of 18-30 years old. The annual number is mostly, accounting for $73.7 \%$ of the total number of respondents.

Tab.1 Basic information of respondents

\begin{tabular}{|c|c|c|c|}
\hline variable & project & People & percentage \\
\hline \multirow{3}{*}{ gender } & male & 122 & 61.6 \\
\cline { 2 - 4 } & female & 76 & 38.4 \\
\hline \multirow{4}{*}{ age } & Under 18 & 2 & 1 \\
\cline { 2 - 4 } & $18-24$ & 85 & 42.9 \\
\cline { 2 - 4 } & $24-30$ & 61 & 30.8 \\
\cline { 2 - 4 } & $30-36$ & 11 & 5.5 \\
\cline { 2 - 4 } & $36-42$ & 11 & 5.5 \\
\cline { 2 - 4 } & More than 42 & 28 & 14.1 \\
\hline
\end{tabular}

\section{2 the consumption habits of badminton enthusiasts}

\subsubsection{Buying considerations}

Multiple response analysis was used to analyze the factors considered by badminton enthusiasts when consuming badminton shirts. The results are shown in Table 2. It can be seen that the most important factors that badminton enthusiasts consider when buying badminton shirts are style, fabric and color.

Tab. 2 Factors to consider when buying badminton shirts

\begin{tabular}{|c|c|c|}
\hline Considerations & $\begin{array}{c}\text { Person- } \\
\text { times }\end{array}$ & percentage \\
\hline Color & 142 & 71.7 \\
\hline Style & 160 & 80.8 \\
\hline Features & 73 & 36.9 \\
\hline Fabric & 150 & 75.8 \\
\hline Price & 120 & 60.6 \\
\hline Brand & 81 & 40.9 \\
\hline Pattern & 82 & 41.4 \\
\hline Other & 7 & 3.5 \\
\hline
\end{tabular}

Cross-analyze age with these three considerations, and the results are shown in Table 3. It can be seen that: for the factor of style, every age group cares about the style of badminton shirts worn; consumers over 30 years of age are more concerned about the fabric of badminton shirts, which can be understood as the performance of the badminton shirt fabrics that consumers care about Whether it meets the physiological conditions of the human body in badminton. For the consideration of color, there are two major age groups. One is the group of teenagers over 18 years of age, the other is the middle-aged group of 36 years and older, and more attention is paid to the color on badminton shirts.

Tab.3 Proportion of choosing badminton shirt fabric and color at different ages

\begin{tabular}{|c|c|c|c|c|}
\hline \multirow{2}{*}{ Age } & \multicolumn{2}{|c|}{ Style } & \multicolumn{2}{c|}{ Fabric } \\
\cline { 2 - 5 } & Count & Proportion & Count & Proportion \\
\hline $18-24$ & 76 & 89.4 & 64 & 75.3 \\
\hline $24-30$ & 50 & 82 & 46 & 75.4 \\
\hline $30-36$ & 9 & 81.8 & 9 & 90 \\
\hline $36-42$ & 7 & 63.6 & 9 & 81.8 \\
\hline$>42$ & 17 & 60.7 & 22 & 78.6 \\
\hline
\end{tabular}

\subsubsection{Badminton Price and Brand}

Fans tend to wear professional badminton shirts with performances such as moisture absorption, breathability and quick-drying for special sports. Brand awareness is that a potential buyer recognizes or remembers a certain brand, and it involves the connection of product categories and brands (Huang et al,2019). 
As shown in Figure 1, the price of badminton shirts generally favored by enthusiasts is basically the same as the price of domestic badminton shirt brands, of which $54 \%$ of consumers choose 100-200 yuan. As can be seen from Figure 2, badminton enthusiasts are more inclined to purchase foreign badminton shirt brands, Yonex and domestic badminton shirt brands are Li Ning and victor, of which Yonex and Li Ning account for $36.9 \%$ and $33.8 \%$ of consumers, respectively.

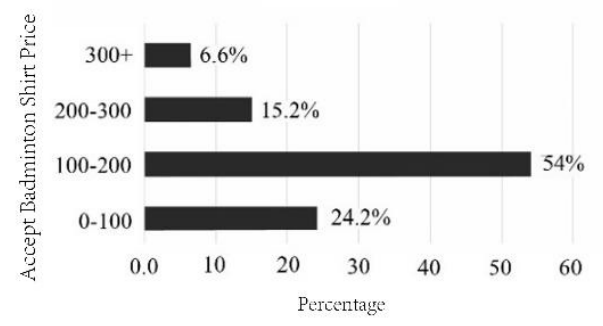

Fig.1 Consumers tend to buy badminton shirts

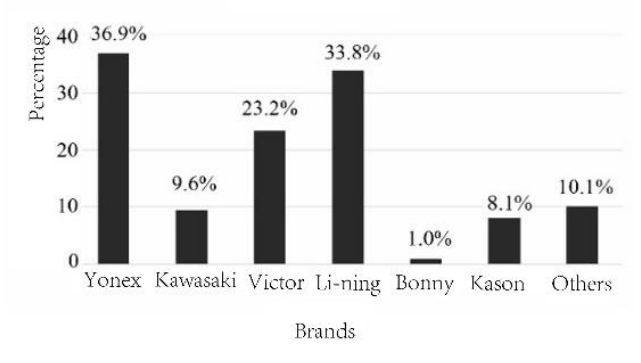

Fig.2 Consumers tend to buy badminton shirts

\subsubsection{Looseness and satisfaction of badminton shirts}

Looseness refers to the spatial line distance formed by the net curved surface of the human body and the inner surface of the garment. It is a margin added to ensure the static and dynamic comfort of the human body and the appearance of the garment (Ma et al,2012), which determines the gap between the human body and the garment range of activities. Due to differences in body shape and personal preferences, badminton lovers have different choices in looseness in clothing. As shown in Figure 3, 56.1\% of consumers prefer badminton shirts with a certain degree of looseness, and $36.9 \%$ of consumers tend to have better fit badminton shirts. Figure 4 shows consumer satisfaction with the badminton shirts currently on the market. $29.3 \%$ of badminton fans are more satisfied with badminton shirts on the market. Badminton fans who are dissatisfied with badminton shirts account for $1.5 \%$, only $1 \%$ of badminton fans are happy with the badminton shirts on the market.

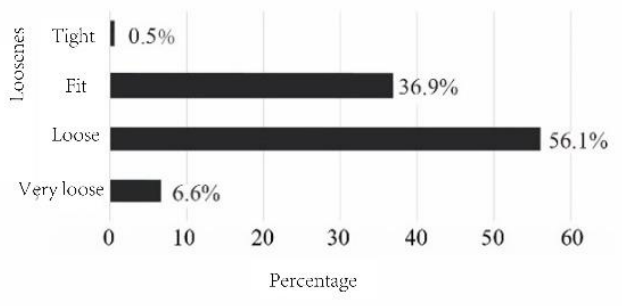

Fig.3 Consumers tend to buy badminton shirts

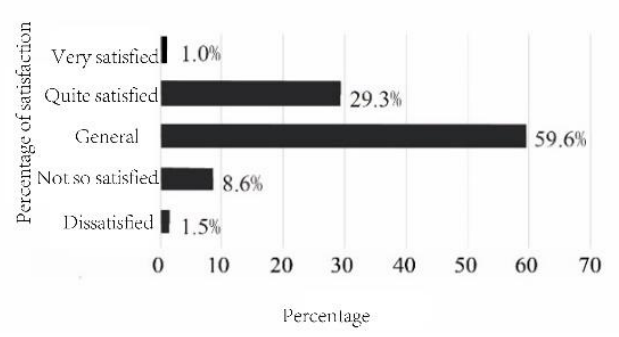

Fig.4 Consumers' satisfaction with badminton shirts

\subsubsection{Problems with badminton shirts}

Badminton is a high-intensity exercise. During exercise, the body emits a lot of heat and sweat. Therefore, it is functionally required that the badminton shirt has good moisture wicking and quick-drying breathability. According to the research on the current badminton shirts in the market, the results are shown in Table $4.67 .7 \%$ of consumers believe that the badminton shirts need to improve their moisture-wicking performance, and $54 \%$ of consumers think they need to improve their comfort.

Tab.4 Problems with badminton shirts

\begin{tabular}{|c|c|c|}
\hline Improvement factor & Person-times & percentage \\
\hline Moisture wicking & 134 & 67.7 \\
\hline Aesthetics & 97 & 49.0 \\
\hline Comfort & 107 & 54.0 \\
\hline Fit & 39 & 19.7 \\
\hline Innovative & 44 & 22.2 \\
\hline
\end{tabular}

\subsection{Impact Analysis of Badminton Shirt Style Preference}

\subsection{1 consumers' preferences and clothing styles by age}

Table 5 shows the preferences of consumers of different ages in clothing styles. By cross-analyzing age with sleeves and collars, it can be found that consumers of each age group are more inclined to wear round sleeves and raglan sleeves. Consumers are more inclined to wear sleeveless badminton shirts; in the choice of collar type, consumers of all ages are more inclined to round neck badminton shirts, this tendency is particularly obvious among consumers aged 36-42 is occupied $54.5 \%$; Among consumers over 42 years old, $28.6 \%$ of enthusiasts tend to choose POLO shirt collars, which is significantly different from consumers of other ages. 
Tab.5 Proportion of style choices for badminton shirts by age and gender

\begin{tabular}{|c|c|c|c|c|c|}
\hline \multirow{2}{*}{$\begin{array}{c}\text { Sleeve / } \\
\text { Collar }\end{array}$} & \multicolumn{5}{|c|}{ Age } \\
\cline { 2 - 6 } & $18-24$ & $24-30$ & $30-36$ & $>42$ & $>42$ \\
\hline $\begin{array}{c}\text { Round } \\
\text { sleeve }\end{array}$ & $47.1 \%$ & $37.7 \%$ & $27.3 \%$ & $45.5 \%$ & $39.3 \%$ \\
\hline Jumpsuit & $14.1 \%$ & $27.9 \%$ & $36.4 \%$ & $18.2 \%$ & $17.9 \%$ \\
\hline $\begin{array}{c}\text { Raglan } \\
\text { sleeves }\end{array}$ & $25.9 \%$ & $14.8 \%$ & $27.3 \%$ & $27.3 \%$ & $28.6 \%$ \\
\hline sleeveless & $12.9 \%$ & $19.7 \%$ & $9.1 \%$ & $9.1 \%$ & $14.3 \%$ \\
\hline $\begin{array}{c}\text { Pointed } \\
\text { collar }\end{array}$ & $23.5 \%$ & $36.1 \%$ & $18.2 \%$ & $45.5 \%$ & $21.4 \%$ \\
\hline $\begin{array}{c}\text { Square } \\
\text { collar }\end{array}$ & $21 . \%$ & $23.0 \%$ & $27.3 \%$ & $0.0 \%$ & $10.7 \%$ \\
\hline \begin{tabular}{c} 
Crew neck \\
\hline$y y y y y$
\end{tabular} & $48.2 \%$ & $36.1 \%$ & $36.4 \%$ & $54.5 \%$ & $39.3 \%$ \\
\hline $\begin{array}{c}\text { POLO } \\
\text { shirt collar }\end{array}$ & $7.1 \%$ & $4.9 \%$ & $18.2 \%$ & $0.0 \%$ & $28.6 \%$ \\
\hline
\end{tabular}

\subsection{Color consumption behavior of badminton fans}

\subsubsection{Buying tendency color matching}

Clothing color is the most direct visual impact of clothing, and it occupies an important role in the aesthetics of clothing. The wearer is the clothing selector and consumer, and also the final determiner of clothing color (Chen et al,2017). Figure 5 shows that $51 \%$ of the respondents tend to wear solid badminton shirts. Consumers generally have a certain tendency to choose colors. Only $12.1 \%$ of the respondents said they do like the gradient color in badminton shirts.

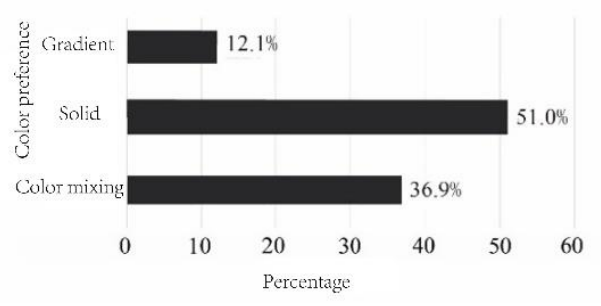

Fig.5 Consumers tend to buy badminton shirts

Table 6 shows the age of the ball and the color preferences of consumers. Cross analysis of the two (Wang,2019). It has been found that badminton enthusiasts of different ball ages generally tend to have fresh and bright badminton shirts. Badminton enthusiasts with a ball age of 5-8 years especially prefer bright badminton shirts. Compared to consumers of all ball ages, $17.2 \%$ of consumers aged $0-2$ did not value the color of badminton shirts, and only $5.3 \%$ of consumers aged more than 10 years did not pay attention to badminton T-shirt colors.
Tab.6 Proportion of different ball ages for the color of badminton shirts

\begin{tabular}{|c|c|c|c|c|c|}
\hline \multirow{2}{*}{$\begin{array}{c}\text { Color } \\
\text { Preference }\end{array}$} & \multicolumn{5}{|c|}{ The year of played badminton } \\
\cline { 2 - 6 } & $0-2$ & $2-5$ & $5-8$ & $8-10$ & $>10$ \\
\hline $\begin{array}{c}\text { Fresh and } \\
\text { bright colors }\end{array}$ & $48.4 \%$ & $56.4 \%$ & $73.7 \%$ & $55.6 \%$ & $36.8 \%$ \\
\hline $\begin{array}{c}\text { Black and } \\
\text { white gray }\end{array}$ & $12.5 \%$ & $11.5 \%$ & $5.3 \%$ & $22.2 \%$ & $31.6 \%$ \\
\hline $\begin{array}{c}\text { Simple and } \\
\text { calm colors }\end{array}$ & $21.9 \%$ & $17.9 \%$ & $10.5 \%$ & $11.1 \%$ & $26.3 \%$ \\
\hline Random & $17.2 \%$ & $14.1 \%$ & $10.5 \%$ & $11.1 \%$ & $5.3 \%$ \\
\hline
\end{tabular}

\section{CONCLUSION}

In the current era, badminton has become a small ball game that can be played indoors and out, which is popular among the masses. It is also a popular sport that is full of fun and can keep fit. The emergence of more and more badminton enthusiasts has driven the development of the badminton industry and also expanded the consumer's choice of badminton clothing. Among the badminton clothing related brands in the market, Yonex, Li Ning and victor occupy a large market share, and other badminton clothing brands are struggling. According to the consumption needs of badminton enthusiasts in Chengdu, this article finds: 1) Consumers' consideration for the purchase of badminton shirts is style, fabric and color in turn. Relevant companies need to pay attention to style development and fabric development, and combine fashion trends to meet consumer demand. 2) More and more consumers attach importance to the beauty of badminton shirts, the comfort and fit of fabrics, and require badminton shirts to meet the sports comfort of clothing and the human body. 3) Consumers of different ages have their own preferences in the style of badminton shirts. Refining the consumer groups of badminton shirts in accordance with the needs of consumers at different age levels can help grasp the direction of the badminton clothing market.4) Most badminton enthusiasts have purchased badminton shirts and tend to buy professional badminton shirts. The purchasing power of enthusiasts is a major driving force for the professional development of badminton shirts in the future.

\section{REFERENCES}

[1] Anonymous. 2019 China Sportswear Industry Market Status and Development Prospect Analysis [R]..http://www.chinaef.com/20190618/649127.html.

[2] Anonymous.Report on the types of sports China often participates in [R] .United States:Cint,20193-26.http://:cint.lanl.gov/publications/ index.php.

[3] LOU Chenyu. Study on Influence of Sweating Condition on Pilling Performance of Knitted Sportswear[J]. Knitting Industries 2019, 5 : 70-72.

[4] LIU Haisang,DONG Zhijia,ZHANG Qi. Size prediction and size modeling of warp knitted seamless sport suits [J].Journal of textile research, 2019, 40 (2) : 76-81. 
[5] Alder DB, Broadbent DP,Stead J,et al.The impact of physiological load on anticipation skills in badminton:From testing to training[J]Journal of sports sciences.2019,16:1816-1823.

[6] CHEN Jianqin,Liu Lei. Contextual Teaching Design of Badminton Sports Technology and Physical Fitness [J]. Teaching of Physical Education.2019, 5, 44-45.

[7] ZOU Qian, ZHAO Li, SHEN Jianming. Research on Comprehensive Performance Evaluation System of Badminton Wear Fabrics [J].Knitting Industries, 2017, $11: 28-32$.

[8] YANG Wei. Establishment of Thermal and Moisture Comfort Evaluation System for Knitted Badminton Wear Fabrics [J]. Melliand China,2017,12:27-38.

[9] CAI Jinfang,MA Dali. Optimization Design of Clothing Market Survey Questionnaire Based on Cognitive Research [J]. Wool Textile Journal,2018,46 (8) : 61-65.

[10] XIONG Heping,LI Shuyi,YU jun .Consumption habits, heterogeneous preferences and asset pricing $[\mathrm{J}]$. Journal of Management Sciences in China,2012,15（9） : 216-217.

[11] LIU Jing,WANG Yongjin. Investigation on Snowboard Wear Evaluation and Demand [J]. Journal of Beijing Institute of Clothing Technology,2018,38 (1) : 42-49.

[12] HUANG Xiuli. Research on Sports Clothing Brand Image Awareness and Marketing Strategy [J].Knitting Industries,2019,1 : 67-70.

[13] MA Suxiang. Research on Influence of Clothing Structure and Loose Amount on Comfort of Table Tennis Wear [D]. Beijing:Beijing Institute of Clothing Technology, 2012.

[14] CHEN Jiahao. Research on Influential Factors of Clothing Color [J]. Wool Textile Journal,2017,45 (6) : 53-55.

[15] WANG Siyu. Fashion Consumption Characteristics of Professional Women in Beijing [J]. Journal of textile research，2019，40 (4) : 165-169. 